18. Olaitan PB, Jiburum BC. Analysis of burn mortality in a burns centre. Ann Burns Fire. Disasters 2006;19(2):59-62. PMID:21991024; PMCID: PMC3188036.

19. Osler T, Glance LG, Hosmer DW. Simplified estimates of the probability of death after burn injuries: extending and updating the Baux score. J Trauma. 2010;68(3):690-7

20. Roberts G, Lloyd M, Parker M, et al. The Baux score is dead. Long live the Baux score: a 27-year retrospective cohort study of mortality at a regional burns service. J Trauma Acute Care Surg. 2012;72(1):251-6.

21. Rosario Aldana MC del, Navarrete N. Epidemiology of a decade of pediatric fatal burns in Colombia, South America. Burns. 2015;41:15871592.

22. Rose JK, Herndon DN. Advances in the treatment of burn patients. Burns 1997;23(1): 19-26.

23. Ryan CM, Schoenfeld DA, Thorpe WP, Sheridan RL, Cassem EH, Tompkins RG. Objective estimates of the probability of death from burn injuries N Engl J Med. 1998;338(6):362-6.

24. Saffle JR, Davis B, Williams P. Recent outcomes in the treatment of burn injury in the United States: a report from the American burn association patient registry. J Burn Care Rehabil. 1995;16,3(1):219-32.
25. Siemers F, Liodaki E, Mauss KL, Stang FH, Wild T von, Mailaender P. Burn Injuries in Elderly - A Retrospective Analysis of a Ten Year Period. Modern Plastic Surgery. 2012;2:13-19.25.

26. Tahir SM, FCPS; Memon AR, MCPS, MS; Kumar M, FCPS; Ali SA FCPS. Prediction of Mortality After Major Burn: Physiological Versus Biochemical Measures. Wounds. 2009;2(7):1 77-182

27. Thombs BD, Singh VA, Milner SM. Children under 4 years are at greater risk of mortality following acute burn injury: evidence from a national sample of 12,902 pediatric admissions. Shock. 2006; 26(4):348-52.

28. Tompkins RG, Burke JF, Schoenfeld DA, et al. Prompt eschar excision: a treatment system contributing to reduced burn mortality: a statistical evaluation of burn care at the Massachusetts General Hospital (1974-1984). Ann Surg. 1986; 204:272-81.

29. Wibbenmeyer LA, Amelon MJ, Morgan LJ, Robinson BK, Chang PX, Lewis II R, et al. Predicting survival in an elderly burn patient population. Burns. 2001;27:583-90.

30. Williams DJ, Walker JD. A nomogram for calculation of the Revised Baux Score. Burns. 2015; 41(1):85-90

31. Zawacki BE, Azen SP, Imbus SH, Chang YT. Multifactorial probit analysis of mortality in burned patients. Ann Surg. 1979;189(1):1-5.

\title{
ХАРАКТЕРИСТИКИ НА ИЗГАРЯНИЯТА В ДЕТСКА ВЪЗРАСТ
}

\author{
Е. Каитева, Д. Радойнова, Й. Заякова
}

\section{CHARACTERISTICS OF THERMAL INJURIES IN CHILDREN}

\author{
E. Kaisheva, D. Radoinova, J. Zaiakova
}

\begin{abstract}
Рез юме. Проучването има за ичел да се определянят факторите от страна на причиняващия агент, на пострадалия организъм и на околната среда от значение за развитието на термичната болест при деца, с иел превенция на тези тежки, а понякога и с фатален изход случаи. За проучването са използвани данни от историите на заболяване на пациенти до 18-годишна възраст, постъпили за лечение в КТТПВЕХ при „МБАЛ-Варна”, за 5-годишен период (20112015 г.). За този период в клиниката са лекувани 565 деца с термична травма, от които 221 момичета (39.1\%) и 344 момчета (60.9\%). Два от случаите са с летален изход. Изгарянията са най-чести във възрастовата група 1-5 г. - 367 (65\%), като повече от 60\% от тях са момчета. Най-често това са попарвания с гореща вода или друга течност - 373 (66,3\%) случаи, в много по-малко случаи изгарянето е контактно или пламъково, съответно 109 (19,4\%) и 55 (9,85\%). При повече от три четвърти от случаите изгарянето обхваща под $10 \%$ от общата телесна повърхност. Получените резултати могат да спомогнат за разработване на програма, целяща намаляването на тези тежки от медицинска, съдебномедиииска, сочиална и икономическа гледна точка случаи.
\end{abstract}

$\boldsymbol{S}$ u $\boldsymbol{m} \boldsymbol{m}$ a ry. The purpose of our study was to identify and determine the characteristics of the factors that are significant for the development of thermal injuries in children: the causing agent, the suffering organism, the environment; in order to prevent these severe and sometimes fatal cases. We used data from patients' histories (aged < 18 years) admitted to the Clinic of Thermal Traumas and Plastic-Restorative and Aesthetic Surgery at the Military Hospital-Varna for a 5 years period (2011-2015). During this period, 565 children with thermal injuries were treated in the clinic (221 girls $/ 39.1 \%$ and 344 boys $/ 60.9 \%)$. Two of the cases had a fatal outcome. The most common cases included hot water or other liquid burns (367/65\%); there were far less cases of contact or flame burns: 109 (19.4\%) and 55 (9.85\%). In more than three quarters of the cases, the burns affected less than 10\% of the total body surface area. It is advisable to analyse the obtained results in order to help develop a program aimed at reducing the severity of these cases from a medical, forensic, social and economic point of view.

Key words: thermal injury, children, thermal factors

\section{Въведение}

Половината от случаите с изгаряне, постьпили в болниците в Европа, са деца $[6,8,15]$. Тези травми са с голямо медицинско, социално и икономическо значение, тъй като дават отражение върху живота на пострадалия, на неговото семейство и на обществото като цяло. При термичната травма е възможно настъпване на летален изход както веднага след получаване на изгарянето, така и на по-късен етап в хода на развитието на термичната болест. Уврежданията са съпроводени със силна болка, деформация и нарушена функция на засегнатата телесна област, обезобразяване, инвалидизиране и налагат скъпоструващи, специализирани медицински грижи и лечение за продължителен период от време [3, 4, $8,15,18,22]$. Проучвания в САЩ и Израел са отчели, че изгарянията са третата по честота причина за смърт сред децата $[20,22]$. Тежестта им, показателите на развилата се термична болест, продължителността на болничното лечение и сроковете за възстановяване зависят от редица фактори като: биомедицински характеристики на пострадалото дете, вид на действалия термичен агент, място на контакт (особености на самата засегната телесна област), механизъм на получаване на увреждането, условия, при които то е получено и продължителност на периода между инцидента и започването на специализирано лечение [15, 16, 29]. 
В разгледаната литература не са намерени данни за провеждано изследване в България на случаите с термична травма при децата, налагаща специализирано болнично лечение.

Настоящото проучване цели да установи и посочи характеристиките на отразените по-горе фактори, имащи значение за развитието на термична болест при децата - от страна на причиняващия агент, на пострадалия организъм, на околната среда, с цел превенция на тези тежки, а понякога и с фатален край случаи.

\section{Материал и методи}

За проучването са използвани данни от историите на заболяване на пациенти от 0 до 18-годишна възраст, приети за лечение в Клиника по термична травма, пластично-възстановителна и естетична хирургия (КТТПВЕХ) при „МБАЛ - Варна", за 5-годишен период (01.01.2011-31.12.2015 г.). Изготвена е обща таблица, в която за всеки пациент (при спазени условия за анонимност) е отразено: възраст, пол, степен на изгарянето, засегната площ (\% от телесната повърхност), вид термичен агент, засегната област от тялото, наличие или не на инхалационно увреждане, продължителност на болничното лечение, изход. Количествените (цифровите) данни са обработени чрез стандартни статистически методи, обобщени и изобразени в Таблици 1-4.

\section{Резултати}

Разгледани са всички случаи с термична травма при деца от 0 до 18-годишна възраст, постъпили за лечение в КТТПВЕХ за посочения пет годишен период.

Общият брой на децата е 565, от които 221 момичета $(39.1 \%)$ и 344 момчета $(60.9 \%)$.

Разпределението на случаите според възрастта на пострадалите е представено на Таблица 1.

Таблица 1. Разпределение на случаите с изгаряне според възрастта на пострадалите

\begin{tabular}{|cr|c|}
\hline Възраст & Брой случаи & $\%$ \\
& & \\
\hline до 1 година & 56 & 10.0 \\
\hline 1 г. 1 м. -2 г. & 209 & 37.0 \\
\hline 2 г. 1 м. -3 г. & 79 & 14.0 \\
\hline 3 г. 1 м. -4 г. & 47 & 8.4 \\
\hline 4 г. 1 м. -5 г. & 26 & 4.6 \\
\hline 5 г. 1 м. -6 г. & 26 & 4.6 \\
\hline 6 г. 1 м. -7 г. & 14 & 2.6 \\
\hline 7 г. 1 м. -8 г. & 18 & 3.2 \\
\hline 8 г. 1 м. -9 г. & 17 & 3.1 \\
\hline 9 г. 1 м. -10 г. & 12 & 2.2 \\
\hline 10 г. 1 м. -11 г. & 4 & 0.7 \\
\hline 11 г. 1 м. -12 г. & 4 & 0.7 \\
\hline 12 г. 1 м. -13 г. & 11 & 2.0 \\
\hline 13 г. 1 м. -14 г. & 7 & 1.4 \\
\hline 14 г. 1 м. -15 г. & 5 & 1.0 \\
\hline 15 г. 1 м. -16 г. & 1 & 0.3 \\
\hline 16 г. 1 м. -17 г. & 9 & 1.7 \\
\hline 17 г. 1 м. -18 г. & 13 & 2.4 \\
\hline
\end{tabular}

Най-много са тези инциденти във възрастта между 1 и 2 г. - 209 (37\% от всички пациенти, постъпили на лечение в клиниката).

При отчитане на факторите пол и възраст, разпределението е представено на Таблица 2.
Таблица 2. Разпределение на случаите с изгаряне при отчитане на факторите пол и възраст

\begin{tabular}{|c|r|r|r|r|r|r|}
\hline \multirow{2}{*}{ Възрастова група } & \multicolumn{2}{|c|}{ Общо } & \multicolumn{2}{|c|}{ Момчета } & \multicolumn{2}{c|}{ Момичета } \\
\cline { 2 - 7 } & \multicolumn{1}{|c|}{ бой } & \multicolumn{1}{|c|}{ брой } & $\%$ & \multicolumn{1}{c|}{ брой } & $\%$ \\
\hline$<12$ месеца & 56 & 9.9 & 42 & 7.4 & 14 & 2.5 \\
\hline $1-5$ години & 367 & 65.0 & 219 & 38.8 & 148 & 26.2 \\
\hline 5 г. 1 м. -18 г. & 142 & 25.1 & 83 & 14.7 & 59 & 10.4 \\
\hline
\end{tabular}

В групата до 1-годишна възраст две трети от пострадалите са момчета. През следващите години съотношението леко се променя, но през цялото време броят на момчетата превалира.

В 24 случая (4.3\%) се отнася за II А степен изгаряне (засягане само повърхностно на дермалния слой на кожата), като разпределението момчета:момичета е 13:11 (54.2:45.8\%). При 414 деца $(73.2 \%)$ е засегната кожната дерма в цялата й дебелина (II В ст.), като разпределението по пол е: 251:163 (60.6:39.4\%) - момчета:момичета. При 127 (22.5\%), момчета:момичета - 80:47 (63:37\%), увреждането преминава през цялата кожа и достига до подкожието (III ст.).

Според площта на изгарянето, изразена в процент от телесната повърхност, разглежданите случаи се разпределят както е преставено в Таблица 3.

Таблица 3. Разпределение на случаите според площта на изгарянето, представена като процент от общзата телесна повърхност

\begin{tabular}{|c|c|c|c|c|c|c|c|}
\hline $\begin{array}{c}\text { Площ в \% } \\
\text { от ТП }\end{array}$ & $0-10$ & $11-20$ & $21-30$ & $31-40$ & $41-50$ & $51-60$ & $61-70$ \\
\hline $\begin{array}{c}\text { Брой случаи } \\
\%\end{array}$ & $\begin{array}{l}494 \\
87.4\end{array}$ & $\begin{array}{l}19 \\
3.4\end{array}$ & $\begin{array}{l}42 \\
7.4\end{array}$ & $\begin{array}{c}4 \\
0.7\end{array}$ & $\begin{array}{c}3 \\
0.5\end{array}$ & $\begin{array}{c}1 \\
0.2\end{array}$ & $\begin{array}{c}2 \\
0.4\end{array}$ \\
\hline
\end{tabular}

Няма нито един пациент със засегнати от изгарянето повече от 70\% от телесната повърхност. В почти $90 \%$ от случаите то е на силно ограничена площ - до $10 \%$ от общата телесна повърхност.

Обособяват се следните типове изгаряне в зависимост от термичния фактор, въздействал върху организма: пламъково - при 55 от случаите, или 9,8\% (момчета 40/момичета 15), попарване 373, 66,3\% (211/162), контактно изгаряне при $109-19.4 \%$ (67/42), от електрически ток $19-3,4 \%(13 / 6)$, химическо $5-0.9 \%(3 / 2)$, слънчево $1-0.2 \%(0 / 1)$.

Попарването е най-честата термична травма. Почти всички такива случаи са инциденти в дома, като в 193 от тях (34,3\%) причинителят е гореща вода, а в 180 (32\%) друга гореща течност - чай, кафе, супа и др. 263 случая $(70.5 \%)$ са при деца под 5-годишна възраст, 38 (10.2\%) под 1 година, a $72(19.3 \%)$ - между 5 и 18 г. Основните засегнати части от тялото са главата, гърдите, корема, горните крайници, предимно предната повърхност на тялото и много по-рядко гърба и седалището. При децата под 5-годишна възраст увреждането от горещата течност често е по различни повърхности на тялото и е както в мястото на първоначален контакт, така и в по-отдалечени области поради стичане на течността по повърхността на тялото. При по-големите деца в повечето случаи е засегната само една телесна повърхност. Разпределението на случаите с попарване, в зависимост от степента на причиненото изгаряне, е: II A - 15 (4\%), II В - 291 (78\%) и III - 67 (18\%).

Контактното изгаряне е второто по честота в детската възраст. Почти във всички случаи се отнася за инциденти в дома, когато детето е оставено без родителски контрол и на достьпно за него място е имало нагорещен предмет - котлон, ютия, печка и др. Тези увреждания се срещат по-често във възрастовата група 1-5 години и значително по-рядко в другите две; при деца до 1 година: 17 (15.6\%), 1-5 години - 76 $(69.7 \%)$ и при тези между 5 и 18 г. - 16 (14.7\%). Разпред- 
елението на случаите по пол е: 67 момчета:42 момичета. Почти при всички случаи засегнатите участьци са с ограничени размери и само в една област и по една телесна повърхност. Степента е II А при 8 случая (7.3\%), II В при 80 $(73.4 \%)$ и III - в $21(19.3 \%)$.

Изгарянето е пламъково в 55 от разглежданите счучаи с термична травма (9.8\%). Съотношението момичета/момчета е 15/40. Най-чести са тези увреждания при по-големите деца, като във възрастовата група 5-18 г. те са 39 (70.9\%), между 1 и 5 г. - 15/27.3\% и само едно (1.8\%) в групата под 1-годишна възраст. Един е случаят, в който пламъкът е предизвикал II А степен изгаряне. В 32 случая (58.2\%) се отнася за II В ст., а в $22(40 \%)$ - за III ст. изгаряне. Основно е засегната предната повърхност на тялото в областта на главата, гърдите и корема, както и горните крайници.

Останалите термични агенти са причина за изгаряне в 25 случая общо. Инцидентите с електротравма са основно при по-големи деца - общо13 случая във възрастта 5-18 г., 6 случая при 1-5-годишните и нито един описан случай за възрастта до 1 година. При 4 деца е установено изгаряне II В степен, а при 15 - III ст.

В 491 от случаите с термична травма $(86.9 \%)$, независимо от вида на агента, причиненото изгаряне е в границите 1-10\%. Разпределението според действалия агент и процента засегната площ е представено в Таблица 4.

Таблица 4. Разпределение на случаите с изгаряне, според вида на термичния агент и проиента засегната площ,

\begin{tabular}{|c|c|c|c|c|c|c|c|c|c|}
\hline \multirow{2}{*}{$\begin{array}{c}\text { Вид } \\
\text { изгаряне }\end{array}$} & \multirow{2}{*}{$\begin{array}{c}\text { Брой } \\
\text { случаи }\end{array}$} & \multirow[b]{2}{*}{$\%$} & \multicolumn{7}{|c|}{ Процент засегната площ } \\
\hline & & & $0-10$ & 111-20 & $21-30$ & $31-40$ & $41-50$ & $51-60$ & $61-70$ \\
\hline пламъково & 55 & 9.8 & 41 & 2 & 7 & & 3 & 1 & \\
\hline контактно & 109 & 19.4 & 108 & & 1 & & & & \\
\hline попарване & 373 & 66.3 & 320 & 14 & 34 & 3 & & & 2 \\
\hline ел. ток & 19 & 3.4 & 16 & 2 & 1 & & & & \\
\hline химическо & 5 & 0.9 & 4 & 1 & & & & & \\
\hline слънчево & 1 & 0.2 & 1 & & & & & & \\
\hline
\end{tabular}

В прегледаните медицински документи на всички деца, постъпили в клиниката за разглеждания пет годишен период, са посочени два смъртни случая. При тях се отнася за попарване, 30\% III ст. и 23\% II В ст., възрастта е 6 г. и 1 г. и 6 м. И при двете деца не е отчетено наличие на инхалационно увреждане. Такова е регистрирано при 7 деца, като всички те са се възстановили.

\section{Обсъжаане}

Етиологията и особеностите на изгарянията при нашето проучване съответстват на тези, докладвани при други подобни изследвания [14, 31].

Половото разпределение на случаите е: $60.9 \%$ момчета и $39.1 \%$ момичета. Подобни са данните, отчетени при редица изследвания $[2,3,5,15,19,23,27]$. Serour и кол., както и други автори посочват дори по-голяма разлика между двата пола момчета/момичета - 69.2\%/30.8\% [24, 26, 28, 32].

При това проучване, подобно на сходни изследвания, е установено, че изгарянията са основно във възрастовата група 1-2 години - 37\% от всички пациенти, постьпили на лечение в клиниката. След 3 годишна възраст броят им рязко спада и продължава да намалява през следващите години до 18 [2, 4, 5, 12, 14, 15, 17, 18, 19, 22-24, 26, 29, 31, 32]. В групата до 1-годишна възраст две трети от пострадалите са момчета. През следващите години съотношението леко се променя, но през цялото време броят на момчетата превалира.

Получените резултати сочат, че най-голям процент от термичните травми са в следствие попарване $-66.3 \%$. Подобни са данните, отчетени и при проучване в Словакия, където то е $73.6 \%, 26.4 \%$ е пламъково изгаряне и значително по-малък процент са останалите $[10,12,14,26,30]$. Такива са стойностите и при други изследвания, като процентът на попарванията варира от 45 до 88 от всички изгаряния [2, 4, $5,9,10,15,16,21,22,24,26-29,31]$.

Настоящото проучване установява пламъково изгарянето в $9.8 \%$ от случаите, което значително се различава от данните от проведено в Кувейт проучване - 23\% от всички изгаряния. За Англия този процент е 12 . На трето място в Кувейт посочват действието на ел. ток - $8 \%$ от децата с термична травма, а в Англия трето по честота е контактното изгаряне $-6 \%$. При нашето изследване, подобно на други, на трето място са пламъковите изгаряния, а на второ - контактните $19.4 \%[1,11,15]$. Коренно се различават резултатите в колумбийско проучване [3], което сочи: пламъково изгаряне $44.1 \%$, ел.ток $-29.9 \%$ и гореща течност $-17.5 \%$ от случаите с изгаряне.

Въпреки че изгарянията при електротравма както при нас, така и в световен мащаб, са значително по-редки и предимно при по-големи деца, те не трябва да се подценяват поради допълнителната им тежест - обикновено са съпроводени и с друга травма, налагат по-продължителен болничен престой и имат по-лоша прогноза с деформации, ампутации, инвалидизиране и смърт $[3,4,28]$.

Почти всички случаи с попарване са инциденти в дома. В 193 случая (34.3\%) причинителят е гореща вода, а в 180 (2\%) друга гореща течност - чай, кафе, супа и др. 263 от тях $(70.5 \%)$ са при деца под 5-годишна възраст, 38 (10.2\%) под 1 година, а $72(19.3 \%)$ - между 5 и 18 г. Най-честият механизъм е детето да излее върху себе си съд, в който се намира течността. Затова основните засегнати части от тялото са главата, гърдите, корема, предимно предната повърхност на тялото и много по-рядко гърба и седалището, горните крайници. Единични са случаите, и то всички във възрастовата група 0-1 година, когато детето е поставено в гореща вода при баня. При по-големите деца се засягат почесто долната част на тялото, долните крайници и дланите. При децата под 5-годишна възраст увреждането от горещата течност често е по различни повърхности на тялото и както в мястото на първоначален контакт, така и в по-отдалечени поради стичане на течността по повърхността на тялото. При по-големите деца в повечето случаи е засегната само една телесна повърхност.

Различни изследователи отчитат, че при децата до 5годишна възраст изгарянията и попарванията са 10 пъти повече, отколкото през коя да е от следващите години до 18, като броят им осезаемо намалява с годините $[7,10,15,17$ $19,24,28]$. Основният им механизъм на получаване е, когато едва прохождащите деца се протягат и достигат до съд (чаша, тенджера, купа и др.) с гореща вода или друга течност, намиращи се върху плот, маса, печка и успяват да го излеят върху себе си $[11,15,17,19]$. При повече от половината случаи с попарване причинител е гореща вода $[2,3,21]$, а в $48 \%$ - друга гореща течност - чай, кафе, мляко, супа, мазнина и др. Това кореспондира с резултатите от други проучвания $[12,21]$. P. Agbenorku отчита дори по-голям процент въздействие на гореща вода - $68.1 \%$ към $32.9 \%$ от други течности $[2,14]$. Balseven-Odabasi и кол. [4] посочват, че в $81.7 \%$ попарването е от гореща вода, $12.1 \%$ - мляко, $1,2 \%$ - мазнина $4.8 \%$ - супа или друга течна храна. Кетр и кол. [15] посочват, че в $59.6 \%$ причинител е гореща течност, в $37.6 \%$ - вода, а в $12.7 \%$ - гореща храна. Видът на действалата течност определя дълбочината (степента) и тежестта на изгарянето. Поплътните течности се задържат по-дълго върху кожата и причиняват по-тежки изгаряния от водата, чая, кафето. Обик- 
новено изгарянията от гореща мазнина са III ст. [21].

Установена е зависимост между вида на термичния агент, механизма на получаване на изгарянето, възрастта на пострадалото дете и разположението по тялото на засегнатото от изгарянето или попарването място. При най-малката възрастова група основно е засегната горната част на тялото, тъй като децата от тази група дърпат съда и изливат върху себе си горещата вода или друга течност [2]. При по-големите деца тези увреждания са с по-малка площ и обикновено са разположени по предната повърхност на тялото, асиметрично $[4,8,15,23]$. Често са засегнати само горните крайници, дори само ръцете. Много рядко при тях са засегнати главата, задната повьрхност на тялото, седалището или гениталиите [15]. Установено е, че площта, засегната от изгарянето в следствие въздействие на гореща течност, е значително поголяма от тази при друг термичен агент. Това коресподира с данните на P. Agbenorku и кол., които отчитат при проучването си значително по-голяма средна засегната при попарването площ - 19,7\% от общата телесна повърхност [2]. При други изследвания са получени различни от посочените резултати - липса на съществена разлика в площта на изгарянето от гореща течност и друг термичен агент $-11.1 \%$ при попарване и 9.8\% при другите изгаряния [12].

Контактното изгаряне е второто по честота в детската възраст. Почти във всички случаи се отнася за инциденти в дома, когато детето е оставено без родителски контрол и на достъпно за него място е имало нагорещен предмет - котлон, ютия, преса за коса, печка и др $[15,17,18,31]$. Затова основна превенция е да не се оставят подобни предмети на пода или на места, достьпни за децата. Тези увреждания се срещат по-често във възрастовата група 1-5 години и значително по-рядко в другите две. При деца до 1 година - 17 (15.6\%), $1-5$ години $-76(69.7 \%)$ и при тези между 5 и 18 г. - 16 $(14.7 \%)$. Основно са инциденти, при които детето хваща такъв предмет, а много по-рядко при залитане пада върху горещ предмет или се допира до него. Разпределението по пол е: 67 момчета : 42 момичета. Почти при всички случаи засегнатите участъци са с ограничени размери и само в една област и по една телесна повърхност. Поради високата температура на нагорещения предмет, чести са по-тежките изгаряния - II В, дори III ст. със засягане на кожата в цялата ѝ дебелина. Подобни резултати отчитат и други изследователи $[13,15]$. Поради по-високата степен на този тип изгаряния, с по-дълбоко проникване до подкожието, дори до подлежащите структури, те крият по-висок риск от смъртен изход и дълготрайно нарушена функция или инвалидизиране поради развитие на контрактури и хипертрофични цикатрикси [15].

Най-тежки са пламъковите изгаряния, за които е характерно засягане не само на цялата кожа и подкожие, но и на подлежащи структури, както и разпространение на поголяма площ от телесната повърхност. Те се срещат предимно при по-големите деца, като във възрастовата група 5-18 г. те са $39(70.9 \%)$, между 1 и 5 г. - $15(27.3 \%)$ и само едно $(1.8 \%)$ в групата под 1-годишна възраст. Основно е засегната предната повърхност на тялото в областта на главата, гърдите и корема, както и горните крайници.

За целия пет-годишен период са отчетени 2 смъртни случая от всички лекувани деца. Подобни резултати се откриват и в други изследвания. Frisman и кол. посочват липса на смъртен изход при отразените от тях случаи [12], а при изследването на Sharma и кол. е установена смъртност от $1,33 \%$ в резултат от пламъково изгаряне, като $82 \%$ от децата са на възраст под 5 години [26]. Balseven-Odabasi и кол. посочват смъртност от 4\%, като всички случаи са били с попарване на деца под 5-годишна възраст [3, 4].

\section{Изводи}

За разглеждания период са отчетени само два смъртни случая. Повечето пострадали деца са момчета. Основната засегната възрастова група е между 1 и 3 г. В 66\% от случаите се отнася за попарване, на второ място са контактните, а на трето - пламъковите изгаряния. В почти $3 / 4$ от случаите се отнася за II В ст. изгаряне, а в почти $1 / 4$ се установява III ст. При около $90 \%$ от пострадалите е засегната под $10 \%$ от общата телесна повърхност. Повечето случаи с изгаряне в детската възраст са инциденти в дома, които са могли да бъдат предвидени и предотвратени. Добре е получените резултати да се анализират и да спомогнат за разработване на програма, целяща намаляването на тези тежки от медицинска, съдебномедицинска, социална и икономическа гледна точка случаи.

\section{Библиография}

1. Abeyasundara S, Rajan V, Lam L, Harvey J, Holland A. The changing pattern of pediatric burns. J of Burn Care \& Research. 2011;32:178-184.

2. Agbenorku P. Early childhood severe scalds in a developing country: A 3year retrospective study. Burns and Trauma. 2013;1(3):122-127.

3. Aldana MC del Rosario, Navarrete N. Epidemiology of a decade of pediatric fatal burns in Colombia, South America. Burns. 2015;41:1587-92.

4. Balseven-Odabasi A, Tumer AR, Keten A, Yorganci K. Burn injuries among children aged up to seven years. The Turkish Journal of Pediatrics. 2009;51:328-335.

5. Berber G, Arslan MM, Özde T. Childhood deaths resulted from burn injuries in Diyarbakır. Eur J Gen Med. 2009;6(1):25-27.

6. Brusselaers N, Monstrey S, Vogelaers D, Hoste E, Blot S. Severe burn injury in Europe: a systematic review of the incidence, etiology, morbidity, and mortality. Crit Care. 2010;14(5):188.

7. Chadova L, Bouska I, Toupalik P. Lethal burn trauma in children. Acta Chir Plast. 2000;42(2):60-3.

8. Davoodi P, Fernandez JM, O. SJ. Postburn sequelae in the pediatric patient: clinical presentations and treatment options. J Craniofac Surg. 2008;19(4):1047-52.

9. Delgado J, Rairez-Carich ME, Gilman RH, et al. Risk factors for burns in children: crowding, poverty and poor maternal aducation. Inj Prev. 2002;8:38-41

10. Duke J, Wood F, Semmens J, et al. A study of burn hospitalizations for children younger than 5 years of age $\%$ 1983-2008. Pediatrics. 2011; 127:971-7.

11. Forjuoh S. Burns in low- and middle-income countries: a review of available literature on descriptive epidemiology, risk factors, treatment, and prevention. Burns. 2006;32:529-37.

12. Frisman E, Racz O, Petrovicova J, Slavik J, Cimbolakova I. Scald burns in children. An analysis with special attention to the roma ethnic group in East Slovakia. International Journal of Clinical Medicine. 2015;6:44-49.

13. Gaffney P. The domestic iron. A danger to young children. J Accid Emerg Med. 2000;17:199-200.

14. Guzel A, Aksu B, Aylanc H, Duran R, Karasalihoglu S. Scald in Pediatric Emergency Department: a 5-year experience. Journal of Burn Care \& Research. 2009; 30:450-456.

15. Kemp AM, Jones S, Lawson Z, Maguire SA. Patterns of burns and scalds in children. Arch Dis Child. 2014;99:316-321.

16. Lorch M, Goldberg J, Wright J et al. Epidemiology and disposition of burn injuries among infants presenting to a tertiary-care pediatric emergency department. Pediatr Emerg Care. 2011;27:1022-6.

17. Maghsoudi H, Samnia N. Etiology and outcome of pediatric burns in Tabriz, Iran. Burns. 2005;31:721-5.

18. Mashreky SR, Rahman A, Chowdhury SM, Giashuddin S, Svanstrom L, Linnan M, et al. Epidemiology of childhood burn: Yield of largest community-based injury survey in Bangladesh. Burns. 2008;34:856-62.

19. Mukerji G, Chamania S, Patidar GP, Gupta S. Epidemiology of paediatric burns in Indore, India. Burns. 2001;27:33-8.

20. National Center for Injury Prevention and Control, CDC, Israel. Leading cases of injury deaths.

21. Parkhouse N. Burns and scalds. Current Paediatrics. 1993;3:67-71.

22. Peleg K, Goldman S, Sikron F. Burn prevention programs for children: do they reduce burn-related hospitalizations? Burns. 2005;31:347-350.

23. Quayle K, Wick N, Gnauck K et al. Description of Missouri children who suffer burn injuries. Inj Prev. 2000;6:255-8.

24. Serour F, Gorenstein A, Boaz M. Characteristics of thermal burns in children admitted to an Israeli pediatric surgical ward. Isr Med Assoc J. 2008; 10:282-6 
25. Shah A, Suresh S, Thomas R, Smith S. Epidemiology and profile of pediatric burns in a large referral center. Clinical Pediatrics. 2011;5:391-395.

26. Sharma PN, Bang RL, Al-Fadhli AN, Sharma P, Bang S, Ghoneim IE. Paediatric burns in Kuwait: Incidence, causes and mortality. Burns. 2006;32:104-111.

27. Tan KT, Prowse PM, Falder S. Ethnic differences in burn mechanism and severity in a UK paediatric population. Burns. 2012;38:551-5.

28. Tarim A, Nursal TZ, Yildirim S, Noyan T, Moray G, Haberal M. Epidemiology of pediatric burn injuries in Southern Turkey. Journal of Burn Care \& Rehabilitation. 2005;26:327-30.
29. Teo A, Van As AB, Cooper J. A comparison of the epidemiology of paediatric burns in Scotland and South Africa. Burns. 2012;38(6):802-6.

30. World Health Organization. The Global burden of disease 2004 update Geneva, Switzerland: World Health Organization. 2008:157.

31. Xu JH, Qiu J, Zhou JH, Zhang L, Yuan DF, Dai W, Gao L. Pediatric burns in Military Hospitals of China from 2001 to 2007: A Retrospective study. Burns. 2014;40:1780-88

32. Zhou B, Zhou X, Ouyang L, Huang X, Zhang M, ren L, Liang P. An epidemiological analysis of paediatric burns in urban and rural areas in South Central China. Burns. 2014;40:150-6.

\title{
Автори
}

Емилия Каишева, УС по съдебна медицина, Медицински университет, Варна, emiliakaisheva@gmail.com;

Добринка Радойнова, Клиника по Съдебна медицина, УБ „Света Марина” ЕАД, Варна, dradoinova@mail.bg;

Йоланда Заякова, Клиника по термична травма, пластично-възстановителна и естетична хирургия „МБАЛ - Варна”, zayakova@yahoo.com

\section{СРАВНИТЕЛЕН АНАЛИЗ НА НАГЛАСИТЕ НА БИЗНЕС-ОПЕРАТОРИ И ПОТРЕБИТЕЛИ ОТНОСНО ВЪВЕЖДАНЕТО НА ДАНЪК „ВРЕДНИ ХРАНИ“}

\author{
Я. Тошкова, Цв. Търпоманова, Д. Янчев, М. Пенкова
}

\section{COMPARATIVE ANALYSIS OF CONSUMER AND BUSINESS OPERATORS ATTITUDES CONCERNING THE INTRODUCTION OF A "HARMFUL FOODS" TAX \\ Y. Toshkova, Tsv. Tarpomanova, D. Yanchev, M. Penkova}

Рез юме. През последните години се увеличава консумацията на преработените храни и храненето в заведения. Това от своя страна води до повишената употреба на енергийно-калорична храна с високо съдържание на транснаситени мазнини, захари и сол. Според експерти прекомерната консумаиия на продукти, които съдържат тези съставки могат да са предпоставка за развитие на хронични незаразни болести - затльстяване, захарен диабет, сърдечносъдови заболявания и някои видове рак. В тази връзка, в България се представя законопроект за данък за обществено здраве (ДОЗ). Целта на настоящата разработка е да се сравнят позищитте на потребителите и бизнес-операторите на храни и напитки относно въвеждането на данък „вредни храни“. Анкетирани са 320 потребители и 51 бизнес-оператори на храни и напитки. Наблюдава се съществена разлика в изразеното мнение на бизнес-операторите и потребителите относно въвеждането на ДОЗ. Над половината от анкетираните потребители (56,5\%) одобряват облагането на храни с т.н. ,вредни съставки“", а в същото време над половината от произведителите $(56,8 \%)$ не одобряват въвеждането на такъв вид данък. Има страни членки на ЕС, в които въведените налози върху храните са отменени поради несъстоятелност на прилагания норматив. По-иелесъобразно би било в нашата страна да се регламентират норми за количествено съдържание на определени съставки (захар, сол, трансмастни киселини, кофеин).

$\boldsymbol{S}$ u $\boldsymbol{m} \mathbf{m}$ a ry. Increased consumption of processed foods leads to an increased use of energy-rich food with a high content of hydrogenated fats, sugars and salt, which is a prerequisite for the development of some socially significant chronic diseases. In this regard, a bill for public health tax (PHT) has been drafted in Bulgaria. The purpose of this paper is to compare the position of consumers and food and beverage business operators on the introduction of the "harmful food" tax. More than half of the respondents $(56.5 \%)$ approve, while $56.8 \%$ of the producers oppose the introduction of such a tax. The majority of the two groups believe that taxation will lead to an increase in the price of the products concerned. According to $58.4 \%$ of consumers, the tax will limit the production of foods containing harmful ingredients. This opinion is maintained by only $15.6 \%$ of the producers. A change in food choices after introducing appropriate marking would be made by $70 \%$ of consumers, but more than half of the business operators have doubts about this choice. Therefore, it would be most appropriate for our country to define norms of the quantitative content of hydrogenated fats, sugars and salt.

Key words: public health tax, "harmful food" tax, consumer, business operator, harmful ingredients (sugar, salt, hydrogenated fats)

\section{Въведение}

С въвеждането на новите технологии при производство на храни и напитки, модернизацията и бързата урбанизация, се променят моделите на хранене не само в развитите, но и в развиващите се страни. Увеличава се консумацията на преработените храни и храненето в заведения. Това, от своя страна, води до повишената употреба на енергийно-калорична храна с високо съдържание на наситени мазнини, трансмаз- нини, захари и сол. [11] Тези съставки подпомагат процесите на производство на храни и напитки, но прекомерната употреба на продукти, които ги съдържат, е предпоставка за развитие на хронични незаразни болести - затльстяване, захарен диабет, сърдечносъдови заболявания и някои видове рак. Затова, по препорька на Световната здравна организация, политиката на Европейския съюз е насочена към ограничаване на консумацията на продукти с високо съдържание на захар, 